\title{
Fluorometric method based on molecular recognition solid-phase extraction for determination of riboflavin in milk and infant formula
}

\author{
Marcelo V. Osó rio ${ }^{\text {a }}$, Sara S. Marques ${ }^{\text {a }}$, Hugo M. Oliveira ${ }^{\mathrm{b}}$, Luisa Barreiros ${ }^{\mathrm{a}, \mathrm{c}}$, Marcela A. Segundo ${ }^{\mathrm{a}}$
}

\author{
${ }^{a}$ UCIBIO, REQUIMTE, Departamento de Ciências Químicas, Faculdade de Farmácia, Universidade do Porto, Rua de Jorge Viterbo Ferreira, 228, 4050-313, Porto, \\ Portugal \\ ${ }^{\mathrm{b}}$ LAQV, REQUIMTE, ICBAS, Universidade do Porto, Rua de Jorge Viterbo Ferreira, 228, 4050-313, Porto, Portugal \\ ${ }^{\mathrm{c}}$ Núcleo de Investigação e Intervenção em Farmácia - NIIF, Centro de Investigação em Saúde e Ambiente - CISA, Escola Sup. Tecnologia da Saúde do Porto - \\ ESTSP, Instituto Politécnico do Porto, Rua Valente Perfeito, 322, 4400-330, Vila Nova de Gaia, Portugal
}

Keywords:

Solid-phase extraction

Molecularly imprinted polymer

Riboflavin

Milk

Infant formula

High-throughput analysis

Microplate

Fluorimetry

Food composition/food analysis

\begin{abstract}
Riboflavin (vitamin $B_{2}$ ) is involved in several biological processes, particularly in energy production, and it is acquired from food ingestion, principally from supplemented food during the first years of life. Therefore, a simple, fast and cost-effective high-throughput method for determination of riboflavin in milk and infant formula is proposed, based on selective extraction using commercially available molecularly imprinted polymers targeted to riboflavin, followed by direct fluorometric determination. Several aspects were studied, namely microplate assay conditions, the composition of eluting solution and the stability of riboflavin in the eluate. Hence, elution using $1 \%(\mathrm{v} / \mathrm{v})$ acetic acid in methanol or in acetonitrile is recommended, followed by immediate analysis or solvent evaporation, with reconstitution and analysis within $24 \mathrm{~h}$. The proposed method provided a LOD of $0.03 \mathrm{mg} \mathrm{L}^{-1}$, with working range for undiluted samples between 0.125 and $2 \mathrm{mg} \mathrm{L}^{-1}$, and sample throughput of $24 \mathrm{~h}^{-1}$. It was successfully applied to certified reference material NIST-1846 and also to commercial milk and infant formula samples.
\end{abstract}

\section{Introduction}

Riboflavin, or vitamin $\mathrm{B}_{2}$, is a water-soluble vitamin composed of an isoalloxazine ring bound to a ribityl side chain (Powers, 2003). This vitamin is the precursor of flavin mononucleotide (FMN) and flavin dinucleotide (FAD) (Henriques et al., 2010), which act as electron carriers in several biological processes and are also cofactors of flavoenzymes such as flavin oxidases, flavin reductases (e.g., glutathione reductase) and flavin dehydrogenases (Depeint et al., 2006).

However, riboflavin cannot be synthesized by the human body, reflecting the importance of its uptake through the diet (Vergani et al., 1999), in the form of FAD, FMN or riboflavin bound to proteins (Henriques et al., 2010; Powers, 2003). Indeed, riboflavin can be found in its free form in milk and eggs or in cereals, vegetables and meat, mostly as FAD (Powers, 2003). Its absorption occurs in its free form, which is afterward converted to FMN and FAD in ATP-dependent processes (Depeint et al., 2006; Henriques et al., 2010).
Riboflavin deficiency has implications on cellular energy production through mitochondrial fatty acid $\beta$-oxidation (Henriques et al., 2010) and mitochondrial respiratory chain (Marriage et al., 2003), on protein synthesis and stabilization (Henriques et al., 2010), haem synthesis, iron mobilization (Fishman et al., 2000; Powers, 2003), protection against oxidative stress (Henriques et al., 2010; Powers, 2003), homocysteine-methionine pathway (Hustad et al., 2000; Powers, 2003), thyroxine metabolism (Powers, 2003) and in other B vitamins metabolism. This vitamin is also important during foetal and infant growth (Ortega et al., 1999) to ensure normal energy production and gastrointestinal tract maturation (Powers, 2003) as well as to guarantee newborn protection against oxidative stress at the time of delivery (Henriques et al., 2010; Powers, 2003). At human body, only liver, cardiac muscle, spleen and kidney are protected organs against riboflavin deficiency (Henriques et al., 2010). For the above stated, adequate riboflavin levels should be assured. 
Therefore, riboflavin quantification in food products is essential and of particular interest in riboflavin-fortified foods, especially for child nutrition, such as milk infant formulas, because riboflavin intake at this age mostly relies on these products (Zand et al., 2012). Furthermore, the decrease of riboflavin content in some foodstuffs and beverages is a quality marker as the degradation of this vitamin is mediated by light exposure (Powers, 2003; Zand et al., 2012). Riboflavin assessment allows to infer about the quality of milk processing and storage (Andrés-Lacueva et al., 1998), as it does for other commodities, because off-flavour formation can occur in such conditions (Manesiotis et al., 2009).

Several methods for quantification of riboflavin in food and beverages have been described, including high-performance liquid chromatography (HPLC)(Gliszczynska-Swiglo and Koziolowa, 2000; Zafra-Gomez et al., 2006) coupled to ultraviolet spectrophotometric (Zand et al., 2012) or to fluorometric (Ndaw et al., 2000) detection, capillary electrophoresis (Cataldi et al., 2002a, 2002b, 2003) coupled to laser-induced fluorescence, and electrochemical methods (Kadara et al., 2006). Generally, quantification of riboflavin is performed by reverse-phase HPLC with fluorescence detection (Koop et al., 2014; Scotter, 2011) preceded by acid hydrolysis and enzymatic treatment in order to convert all riboflavin content into free riboflavin, and by an extraction technique to remove interferences (Ndaw et al., 2000; Segundo et al., 2012; Zand et al., 2012).

Solid-phase extraction (SPE) is widely used for sample pretreatment (He et al., 2007; Hennion, 1999) and is a suitable technique for riboflavin extraction and pre-concentration from food samples as well as for the elimination of matrix interferences prior to HPLC analysis (Segundo et al., 2012). Furthermore, flow injection techniques have been applied in the automation of SPE procedures, contributing to more accurate, precise, and less laborious processes (He et al., 2007; Oliveira et al., 2010). However, SPE with classic sorbents, namely $\mathrm{C} 18$ or conventional polymeric structures, usually leads to co-extraction of interferences due to the non-selective interactions established between the sorbent and the target analyte (Pichon, 2007). In order to overcome this drawback, molecularly imprinted polymers (MIP) have been developed as a revolutionary type of SPE sorbent, allowing higher selectivity due to specific molecular recognition of the analyte (Haupt and Mosbach, 2000).

In fact, a MIP for selective recognition of riboflavin was developed employing 2,6-bis(acrylamide)pyridine as functional monomer due to its hydrogen-bond interactions with the riboflavin imide group (Manesiotis et al., 2005, 2009). Riboflavin tetra-acetate, an analogue of the target molecule, was chosen as template (Manesiotis et al., 2005), ensuring that the target analyte is strongly retained and that the obtained results are not affected by template bleeding (Pichon, 2007). Pentaerythritol triacrylate was used as cross-linking agent (Manesiotis et al., 2005; Oliveira et al., 2010), permitting specific extraction in aqueous media. A porogen was also employed in the polymerization process to suppress non-specific binding to sorbent in an aqueous medium (Manesiotis et al., 2009).

Considering all the time-consuming steps involved in current methods, a new high-throughput protocol for riboflavin assessment in milk by molecularly imprinted solid phase-extraction (MISPE) followed by direct fluorometric detection under microplate format is proposed. Microplate assay conditions and MISPE parameters were assessed, targeting application towards real samples.

\section{Materials and methods}

\subsection{Chemicals}

All reagents were of analytical grade and purchased from Sigma Aldrich (St. Louis, MO, USA) if not specified. Water was obtained from arium water purification systems (resistivity $>18 \mathrm{M} \Omega \mathrm{cm}$, Sartorius, Goettingen, Germany).

Glacial acetic acid was diluted in order to prepare $1 \%$ and $2.4 \%(\mathrm{v} / \mathrm{v}) \mathrm{CH}_{3} \mathrm{COOH}$ aqueous solution, $1 \%(\mathrm{v} / \mathrm{v}) \mathrm{CH}_{3} \mathrm{COOH}$ in $\mathrm{CH}_{3} \mathrm{CN}$ and $1 \%(\mathrm{v} / \mathrm{v}) \mathrm{CH}_{3} \mathrm{COOH}$ in $\mathrm{CH}_{3} \mathrm{OH}$. $\mathrm{CH}_{3} \mathrm{CN}$ and $\mathrm{CH}_{3} \mathrm{OH}$ (both HPLC grade) were purchased from Merck (Darmstadt, Germany).

Riboflavin stock solutions were prepared by dissolving $5.00 \mathrm{mg}$ of riboflavin in $100 \mathrm{~mL}$ of water, $3.0 \mathrm{mM} \mathrm{HCl}$ or $2.4 \%(\mathrm{v} / \mathrm{v})$ $\mathrm{CH}_{3} \mathrm{COOH}$ aqueous solution. This solution was heated at $37^{\circ} \mathrm{C}$ for $10 \mathrm{~min}$ to ensure complete dissolution of riboflavin. After cooling, riboflavin standard solutions were prepared by dilution of the stock solution in the respective solvent. All riboflavin solutions were kept in the dark at $4{ }^{\circ} \mathrm{C}$.

The MIP selective towards riboflavin was supplied by Supelco (Bellefonte, PA, USA) in cartridges comprising $25 \mathrm{mg}$ of sorbent with a volume capacity of $10 \mathrm{~mL}$. MISPE was performed with $1 \%$ (v/v) $\mathrm{CH}_{3} \mathrm{COOH}$ in $\mathrm{CH}_{3} \mathrm{CN}, 1 \%(\mathrm{v} / \mathrm{v}) \mathrm{CH}_{3} \mathrm{COOH}$ in $\mathrm{CH}_{3} \mathrm{OH}$ or $70 \%(\mathrm{v} / \mathrm{v})$ $\mathrm{CH}_{3} \mathrm{CN}$ in water as elution solvents.

\subsection{MISPE protocol}

MISPE was performed in a commercial system supplied by Supelco (Bellefonte, PA, USA). The system was coupled to a vacuum pump (Büchi, Flawil, Switzerland) and allowed the simultaneous extraction of 12 samples. Sorbent conditioning was performed by percolation of $1.0 \mathrm{~mL}$ of methanol followed by $1.0 \mathrm{~mL}$ of ultra-pure water. Then, $1.00 \mathrm{~mL}$ of sample or standard solution was loaded into the sorbent column at $0.5 \mathrm{~mL} \mathrm{~min}^{-1}$, after which the column was dried under vacuum for $10 \mathrm{~min}$. The elimination of matrix interferences was performed by percolation of $2.0 \mathrm{~mL}$ of ultra-pure water, followed by column drying under vacuum for $1 \mathrm{~min}$. The elution of riboflavin was performed with 3 portions of $1.0 \mathrm{~mL}$ each of elution solvent at $0.2 \mathrm{~mL} \mathrm{~min}^{-1}$. The eluate was then analyzed by fluorometry or dried and reconstituted in an appropriate solvent before analysis.

\subsection{Microplate protocol for fluorometric determination}

Fluorometric determinations were performed in a highthroughput 96-well microplate reader (Synergy HT; Bio-Tek Instruments, Winooski, VT, USA; $\lambda$ exc $=380 \mathrm{~nm}, \lambda$ em $=528 \mathrm{~nm}$ ). A $300-\mu \mathrm{L}$ aliquot of sample or riboflavin standard prepared with the same eluate composition was placed in a 96-well microplate, as depicted schematically in Fig. S1. Using the proposed layout, 13 samples were analyzed in triplicate, with concomitant analysis of 5 standards $(n=3)$. Hence, sample blank was performed with $300 \mu \mathrm{L}$ of $1 \%(\mathrm{v} / \mathrm{v}) \mathrm{CH}_{3} \mathrm{COOH}$ solution in $\mathrm{A} 1-\mathrm{C} 1$ wells, while standards (concentration range of $0.125-2.00 \mathrm{mg} \mathrm{L}^{-1}$ ) were placed in A2-C6 wells. The remaining wells were filled with samples extracted in duplicate and analyzed in triplicate each.

\subsection{Evaluation of the elution conditions and eluate stability}

To assess the appropriate solvent for reconstitution of the dried eluate after evaporation, $3 \mathrm{~mL}$ of a riboflavin solution $\left(0.33 \mathrm{mg} \mathrm{L}^{-1}\right)$ prepared in $1 \%(\mathrm{v} / \mathrm{v}) \mathrm{CH}_{3} \mathrm{COOH}$ in $\mathrm{CH}_{3} \mathrm{CN}$ were placed at $90{ }^{\circ} \mathrm{C}$ until solvent evaporation and the residue was dissolved in $1 \mathrm{~mL}$ of $\mathrm{H}_{2} \mathrm{O}$ or $1 \%(\mathrm{v} / \mathrm{v}) \mathrm{CH}_{3} \mathrm{COOH}$ in $\mathrm{H}_{2} \mathrm{O}$, providing similar recoveries.

In order to evaluate the possibility of analyte determination on a different day of MISPE performance, a riboflavin solution ( $1 \mathrm{mg} \mathrm{L}^{-1}$ ) prepared in $2.4 \%(\mathrm{v} / \mathrm{v}) \mathrm{CH}_{3} \mathrm{COOH}$ in $\mathrm{H}_{2} \mathrm{O}$ was submitted to MISPE. Elution solvents tested were $1 \%(\mathrm{v} / \mathrm{v}) \mathrm{CH}_{3} \mathrm{COOH}$ in $\mathrm{CH}_{3} \mathrm{CN}, 1 \%(\mathrm{v} / \mathrm{v}) \mathrm{CH}_{3} \mathrm{COOH}$ in $\mathrm{CH}_{3} \mathrm{OH}$ and $70 \%(\mathrm{v} / \mathrm{v}) \mathrm{CH}_{3} \mathrm{CN}$ in $\mathrm{H}_{2} \mathrm{O}$. Thereafter, the obtained eluate was analyzed immediately and on the day after MISPE. Moreover, the eluate was also submitted to the solvent evaporation step described above and analyzed 
immediately, on the day after or a week after MISPE, after reconstitution with $1 \%(\mathrm{v} / \mathrm{v}) \mathrm{CH}_{3} \mathrm{COOH}$ in $\mathrm{H}_{2} \mathrm{O}$.

For the direct fluorometric detection methodology, $100 \mu \mathrm{L}$ of each eluate obtained with $1 \%(\mathrm{v} / \mathrm{v}) \mathrm{CH}_{3} \mathrm{COOH}$ in $\mathrm{CH}_{3} \mathrm{CN}$ or $1 \%(\mathrm{v} / \mathrm{v})$ $\mathrm{CH}_{3} \mathrm{COOH}$ in $\mathrm{CH}_{3} \mathrm{OH}$ were diluted 10 times with $1 \%(\mathrm{v} / \mathrm{v}) \mathrm{CH}_{3} \mathrm{COOH}$ in water. The eluate obtained with $70 \%(\mathrm{v} / \mathrm{v}) \mathrm{CH}_{3} \mathrm{CN}$ in water was further diluted in water. An aliquot of the diluted eluate was kept in the dark at $4{ }^{\circ} \mathrm{C}$ for analysis on the following day.

For fluorometric analysis after eluent evaporation, an aliquot of the obtained eluate was dried at $90{ }^{\circ} \mathrm{C}$. Replicates were made in order to analyze the dry residue on different days after extraction, which were kept in the dark at $4{ }^{\circ} \mathrm{C}$. Dry residue was reconstituted in $1 \%(\mathrm{v} / \mathrm{v}) \mathrm{CH}_{3} \mathrm{COOH}$ in $\mathrm{H}_{2} \mathrm{O}$ prior to fluorometric analysis.

\subsection{Application to samples}

Certified reference sample (CRM) NIST-1846 (infant formula milk-based) was supplied by LGC Standards (Teddington, UK) while milk and other infant formula samples were purchased from a local market. CRM infant formula was prepared by dissolving $25.00 \mathrm{~g}$ of sample in $100 \mathrm{~mL}$ of hot water (approximately $90{ }^{\circ} \mathrm{C}$ ). After cooling, this solution was transferred to a 250-mL volumetric flask and the remaining volume was made up with water. Milk samples were used immediately after opening the package. Powdered samples (1,2 and 3 ) were dissolved following manufacturer's instructions, in order to attain riboflavin concentrations as given on the label. Other samples (4 and 5) were evaluated without any prior treatment. For CRM, the extraction protocol was performed with different elution solutions: $1 \%(\mathrm{v} / \mathrm{v}) \mathrm{CH}_{3} \mathrm{COOH}$ in $\mathrm{CH}_{3} \mathrm{CN}, 1 \%(\mathrm{v} / \mathrm{v}) \mathrm{CH}_{3} \mathrm{COOH}$ in $\mathrm{CH}_{3} \mathrm{OH}$ and $70 \%(\mathrm{v} / \mathrm{v}) \mathrm{CH}_{3} \mathrm{CN}$ in $\mathrm{H}_{2} \mathrm{O}$. Other samples were eluted with $1 \%(\mathrm{v} / \mathrm{v}) \mathrm{CH}_{3} \mathrm{COOH}$ in $\mathrm{CH}_{3} \mathrm{OH}$. Each eluate was diluted (1:10) in $1 \%(\mathrm{v} / \mathrm{v}) \mathrm{CH}_{3} \mathrm{COOH}$ in $\mathrm{H}_{2} \mathrm{O}$, except when $70 \%(\mathrm{v} / \mathrm{v}) \mathrm{CH}_{3} \mathrm{CN}$ in $\mathrm{H}_{2} \mathrm{O}$ was employed. The concentration in the diluted eluate was determined by fluorometry.

\section{Results and discussion}

\subsection{Parameters of riboflavin fluorometric determination}

Several physico-chemical parameters affect the sensitivity of fluorometric determination of riboflavin, namely the volume placed in the microplate well and the solvent applied. Hence, increasing volumes $(100,200,250$ and $300 \mu \mathrm{L})$ of riboflavin standards $\left(0.15-11 \mathrm{mg} \mathrm{L}^{-1}\right.$, prepared in $\left.2.4 \%(\mathrm{v} / \mathrm{v}) \mathrm{CH}_{3} \mathrm{COOH}\right)$ were analyzed by spectrophotometry $(\lambda=370 \mathrm{~nm})$ and fluorometry. The slope of calibration curves based on absorbance $v s$ concentration was proportional to the volumes applied $(33.3,70.8,87.5 \%$ of that obtained for $300 \mu \mathrm{L}$, considering the increasing tested volumes) because in microplates the optical path length is defined by the volume placed in each well. For fluorescence measurements, the slope of calibration curves based on fluorescence intensity $v s$ concentration was not proportional to the volumes applied (18.5, 49.2, and $69.0 \%$ of that obtained for $300 \mu \mathrm{L}$, considering the increasing tested volumes). For fluorescence measurements, taken at the top of the microplate, more solution will be probed if the well is filled, with a larger decrease in sensitivity if less solution is placed inside each well. Hence, the largest possible volume $(300 \mu \mathrm{L})$ was chosen for further determinations.

Considering that different eluents can be applied to MISPE, riboflavin standards were prepared in water, $1 \%(\mathrm{v} / \mathrm{v}) \mathrm{CH}_{3} \mathrm{COOH}$ in water, $1 \%(\mathrm{v} / \mathrm{v}) \mathrm{CH}_{3} \mathrm{COOH}$ in $\mathrm{CH}_{3} \mathrm{CN}, 1 \%(\mathrm{v} / \mathrm{v}) \mathrm{CH}_{3} \mathrm{COOH}$ in $\mathrm{CH}_{3} \mathrm{OH}$ and $70 \%(\mathrm{v} / \mathrm{v}) \mathrm{CH}_{3} \mathrm{CN}$ in water, in order to evaluate the solvent role upon the sensitivity of the fluorometric determination between 0.005 and $0.04 \mathrm{mg} \mathrm{L}^{-1}$.

As depicted in Fig. 1, the best sensitivity was attained using water as solvent, followed by $1 \%(\mathrm{v} / \mathrm{v}) \mathrm{CH}_{3} \mathrm{COOH}$ in water, with $\mathrm{ca}$. $80 \%$ of the sensitivity achieved with water. Small differences $(<6 \%)$ in the sensitivity were attained for both aqueous solutions containing acetic acid. In order to evaluate if this effect is due to $\mathrm{pH}$ or acetic acid itself, riboflavin solutions were prepared in $2.4 \%$ $(\mathrm{v} / \mathrm{v}) \mathrm{CH}_{3} \mathrm{COOH}$ in water and $3.0 \mathrm{mM} \mathrm{HCl}$, providing the same $\mathrm{pH}$ value $(\mathrm{pH}=2.5)$. Similar sensitivity was achieved, confirming the importance of $\mathrm{pH}$ on the sensitivity. In fact, previous reports indicate that quantum yields of riboflavin are highly $\mathrm{pH}-$ dependent, with maximum values in the range 4-8 (Drossler et al., 2002). Therefore, pure organic solvents (e.g., methanol and acetonitrile) were not regarded as suitable eluents.

Moreover, a decrease in sensitivity was found (Fig. 1) when an organic solvent was present. In fact, it was observed that solutions prepared in $1 \%(\mathrm{v} / \mathrm{v}) \mathrm{CH}_{3} \mathrm{COOH}$ in $\mathrm{CH}_{3} \mathrm{CN}, 1 \%(\mathrm{v} / \mathrm{v}) \mathrm{CH}_{3} \mathrm{COOH}$ in $\mathrm{CH}_{3} \mathrm{OH}$ and $70 \%(\mathrm{v} / \mathrm{v}) \mathrm{CH}_{3} \mathrm{CN}$ in $\mathrm{H}_{2} \mathrm{O}$ adhered to the microplate walls, forming a pronounced concave meniscus. As the detection occurs at the top of the microplate, this effect can account for the

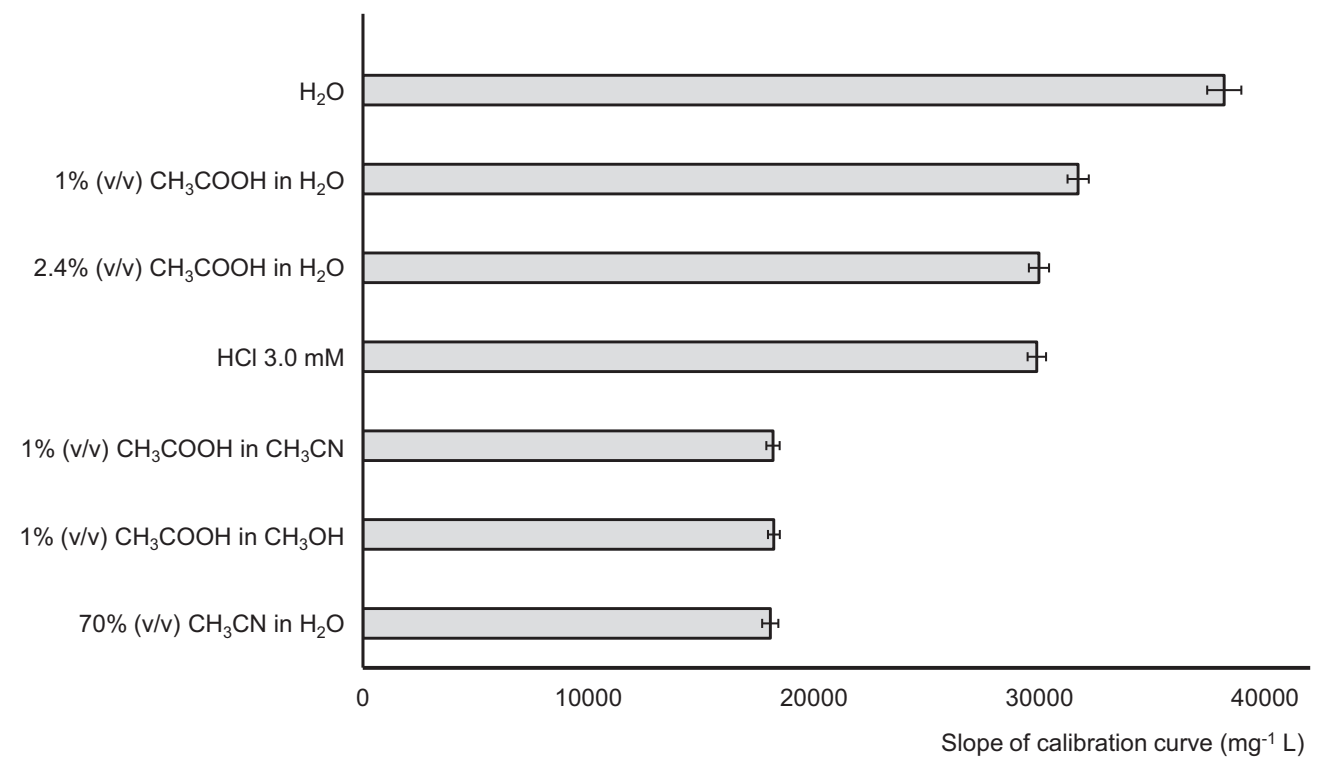

Fig. 1. Sensitivity of fluorometric determination of riboflavin (concentration range $0.005-0.04 \mathrm{mg} \mathrm{L}^{-1}$ ) using different solvents ( $n=8$ ) 


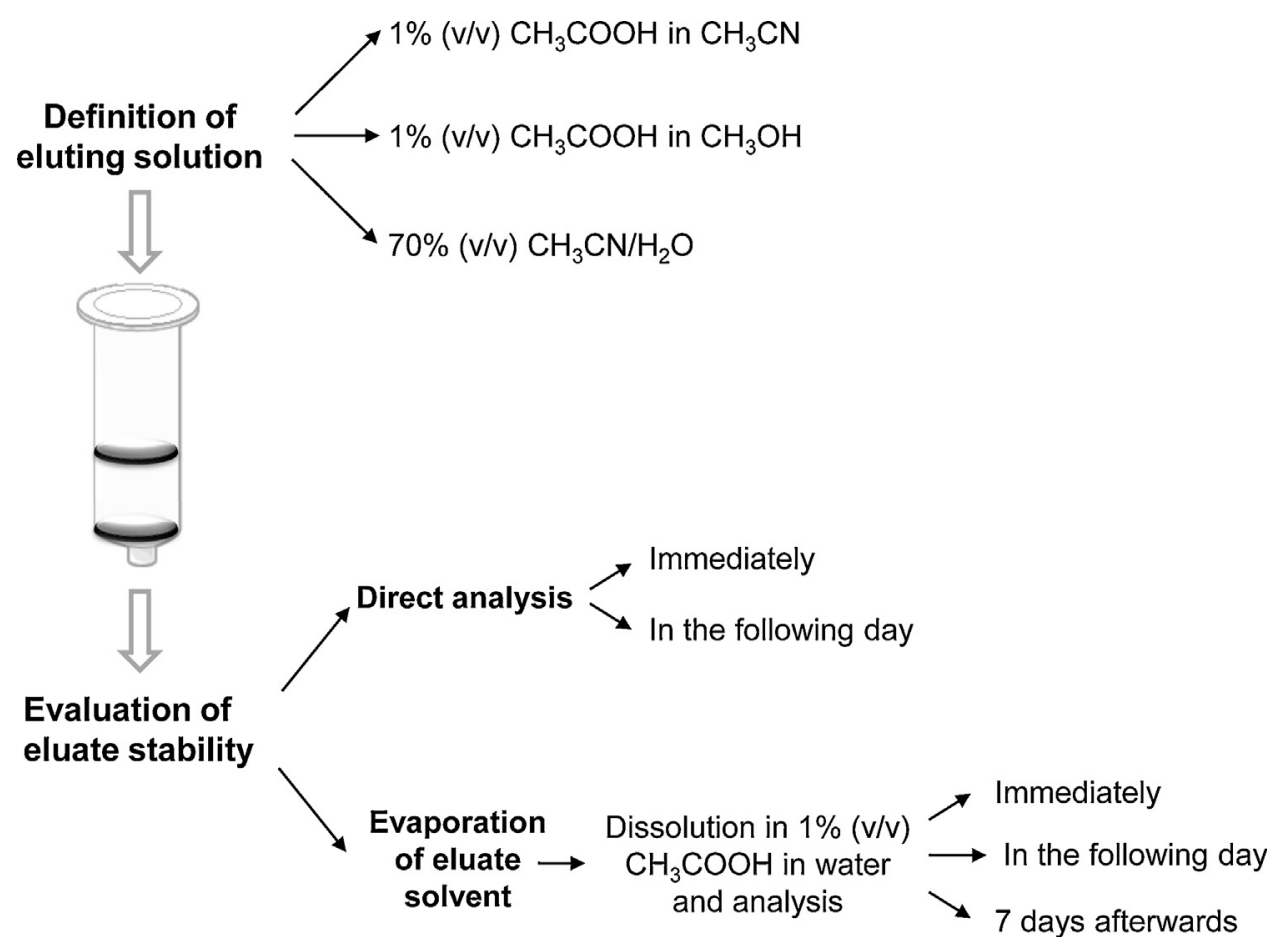

Fig. 2. Experimental setup for evaluating eluate stability using different eluting solutions.

lower sensitivity attained. Similar results were found for riboflavin solutions in the concentration range $0.04-0.6 \mathrm{mg} \mathrm{L}^{-1}$.

\subsection{Evaluation of elution conditions and eluate stability}

Flow rates for sample and eluent passage through SPE sorbents are extremely important as they define the time allowed for interaction and mass transfer upon sample loading and retention of analytes in the sorbent, followed by their desorption into the eluent. Hence, sample loading and elution flow rates were fixed at 0.5 and $0.2 \mathrm{~mL} \mathrm{~min}^{-1}$, respectively, as a compromise between a high sample throughput and enough time to allow a quantitative recovery of riboflavin. Moreover, eluent volume was fixed at $3 \times$ $1.0 \mathrm{~mL}$ in order to guarantee total elution of riboflavin.

As schematically depicted in Fig. 2, several eluting solutions were tested. Furthermore, the eluate stability was assessed by immediate analysis $v s$ analysis $24 \mathrm{~h}$ after elution. Finally, to investigate the feasibility of storing processed samples for further analysis, eluate solvent was evaporated and the eluate residue was dissolved in $1 \%(\mathrm{v} / \mathrm{v}) \mathrm{CH}_{3} \mathrm{COOH}$ in water at the same day, $24 \mathrm{~h}$ and 7 days after elution. Results are given in Table 1, showing that the eluate solvent removal and reconstitution did not affect the analyte recovery $(0.053<P<0.299$, Fig. S2). Moreover, recoveries $>90 \%$ were attained for all eluting solutions containing $1 \%(\mathrm{v} / \mathrm{v}) \mathrm{CH}_{3} \mathrm{COOH}$, analyzed in the same day or $24 \mathrm{~h}$ later if the eluate solvent was removed immediately after extraction. Lower recoveries (83.9-84.1\%) were attained for $70 \% \mathrm{CH}_{3} \mathrm{CN}$ in water (Fig. S3, $P<0.00001$ when compared to other solvents). This effect may be explained by the promotion of riboflavin desorption from the MIP mediated by acetic acid. In fact, riboflavin triacetate was the template molecule applied upon MIP synthesis. After retention of riboflavin, the presence of acetic acid will weaken its interaction to the sorbent, promoting riboflavin desorption in a timeframe acceptable for quantitative analysis (Manesiotis et al., 2005).

Concerning the eluate stability, lower recoveries (70.2-76.1\%) were attained for all eluting solutions analyzed on the day after extraction if the eluent solvent is not removed (Fig. S4; $P<0.00001$ ). Upon eluent evaporation and reconstitution on the following day, recoveries were similar to those achieved upon analysis immediately after extraction for all eluting solutions. However, a decrease of $10 \%$ was observed if the dry residue was reconstituted one week later.

Table 1

Evaluation of analyte stability using different elution solvents, analyzed at different moments after extraction.

\begin{tabular}{|c|c|c|c|c|}
\hline \multirow[t]{2}{*}{ Methodology } & \multirow[t]{2}{*}{ Time of analysis } & \multicolumn{3}{|l|}{ Riboflavin mass $(\mu \mathrm{g})^{\mathrm{a}}$} \\
\hline & & $1 \%(\mathrm{v} / \mathrm{v}) \mathrm{CH}_{3} \mathrm{COOH}$ in $\mathrm{CH}_{3} \mathrm{CN}$ & $1 \%(\mathrm{v} / \mathrm{v}) \mathrm{CH}_{3} \mathrm{COOH}$ in $\mathrm{CH}_{3} \mathrm{OH}$ & $70 \%(\mathrm{v} / \mathrm{v}) \mathrm{CH}_{3} \mathrm{CN} / \mathrm{H}_{2} \mathrm{O}$ \\
\hline Direct eluate analysis & $\begin{array}{l}\text { On the same day } \\
\text { On the following day }\end{array}$ & $\begin{array}{l}0.908 \pm 0.003 \\
(90.8 \pm 0.3 \%) \\
0.757 \pm 0.002 \\
(75.7 \pm 0.2)\end{array}$ & $\begin{array}{l}0.914 \pm 0.002 \\
(91.0 \pm 0.2) \\
0.764 \pm 0.002 \\
(76.1 \pm 0.2)\end{array}$ & $\begin{array}{l}0.844 \pm 0.002 \\
(84.1 \pm 0.2) \\
0.705 \pm 0.002 \\
(70.2 \pm 0.2)\end{array}$ \\
\hline $\begin{array}{l}\text { Analysis after evaporation } \\
\text { and eluate reconstitution }\end{array}$ & $\begin{array}{l}\text { On the same day } \\
\text { On the following day } \\
\text { One week afterwards }\end{array}$ & $\begin{array}{l}0.880 \pm 0.001 \\
(91.0 \pm 0.1) \\
0.879 \pm 0.001 \\
(90.9 \pm 0.1) \\
0.756 \pm 0.001 \\
(78.18 \pm 0.1)\end{array}$ & $\begin{array}{l}0.883 \pm 0.001 \\
(90.9 \pm 0.1) \\
0.883 \pm 0.001 \\
(90.9 \pm 0.1) \\
0.762 \pm 0.001 \\
(78.5 \pm 0.1)\end{array}$ & $\begin{array}{l}0.815 \pm 0.001 \\
(83.9 \pm 0.1) \\
0.815 \pm 0.001 \\
(83.9 \pm 0.1) \\
0.702 \pm 0.001 \\
(72.3 \pm 0.1)\end{array}$ \\
\hline
\end{tabular}

a Values between parenthesis indicate the recovery percentage. 
Table 2

Determination of riboflavin in commercial milk samples by the proposed procedure.

\begin{tabular}{|c|c|c|c|}
\hline Commercial milk samples & Concentration found $\left(\mathrm{mg} \mathrm{L}^{-1}\right)$ & Concentration on label $\left(\mathrm{mg} \mathrm{L}^{-1}\right)$ & Composition (on label, per $100 \mathrm{~mL}$ ) \\
\hline Sample 1 (powdered milk) & $1.012 \pm 0.004$ & 1.11 & Proteins $2.3 \mathrm{~g}$, carbohydrates $8.6 \mathrm{~g}$, lipids $4.2 \mathrm{~g}$ \\
\hline Sample 2 (low fat powdered milk) & $1.985 \pm 0.005$ & 2.18 & Proteins $3.8 \mathrm{~g}$, carbohydrates $6.0 \mathrm{~g}$, lipids $0.1 \mathrm{~g}$ \\
\hline Sample 3 (infant formula) & $1.004 \pm 0.003$ & 1.10 & Proteins $1.5 \mathrm{~g}$, carbohydrates $8.5 \mathrm{~g}$, lipids $2.8 \mathrm{~g}$ \\
\hline Sample 4 (milk with strawberry pulp) & $1.366 \pm 0.005$ & 1.50 & Proteins $3.2 \mathrm{~g}$, carbohydrates $8.7 \mathrm{~g}$, lipids $1.1 \mathrm{~g}$ \\
\hline Sample 5 (infant formula) & $1.094 \pm 0.004$ & 1.20 & Proteins $2.5 \mathrm{~g}$, carbohydrates $6.3 \mathrm{~g}$, lipids $3.0 \mathrm{~g}$ \\
\hline
\end{tabular}

Hence, elution using $1 \%(\mathrm{v} / \mathrm{v}) \mathrm{CH}_{3} \mathrm{COOH}$ in $\mathrm{CH}_{3} \mathrm{CN}$ or in $\mathrm{CH}_{3} \mathrm{OH}$ is recommended, followed by immediate analysis or solvent evaporation, with reconstitution and analysis within $24 \mathrm{~h}$.

\subsection{Analytical features and application to samples}

The proposed methodology allows the determination of riboflavin at a large concentration range $\left(0.0063-2.0 \mathrm{mg} \mathrm{L}^{-1}\right)$, fostered by adjusting the signal gain in the fluorometric detector. This means that infant formula and milk samples can be analyzed after 10 times dilution of the respective eluate using $1 \%(\mathrm{v} / \mathrm{v})$ $\mathrm{CH}_{3} \mathrm{COOH}$ in water, avoiding the excessive use of organic solvents in the microplates. In fact, eluate from $1.00 \mathrm{mg} \mathrm{L}^{-1}$ solution was analyzed undiluted or after 10 times dilution using $1 \%(\mathrm{v} / \mathrm{v})$ $\mathrm{CH}_{3} \mathrm{COOH}$ in water. Recovered mass values of riboflavin were not significantly different $\left(t_{\text {tabulated }}(\alpha=0.05, \mathrm{df}=10)=2.23, t_{\text {calculated }}=\right.$ 0.049 ). The estimated detection limit was $3.4 \mu \mathrm{g} \mathrm{L}^{-1}$, equivalent to $34 \mu \mathrm{g} \mathrm{L}^{-1}$ in the undiluted samples.

To evaluate the accuracy of the proposed MISPE highthroughput procedure, infant formula reference material NIST1846 (17.4 $\pm 1.0 \mathrm{mg} \mathrm{kg}^{-1}$ in riboflavin) was analyzed using the different elution solutions tested before. Using $1 \%(\mathrm{v} / \mathrm{v}) \mathrm{CH}_{3} \mathrm{COOH}$ in $\mathrm{CH}_{3} \mathrm{CN}$ as eluting solution, the concentration value obtained was $15.94 \pm 0.32 \mathrm{mg} \mathrm{kg}^{-1}$, corresponding to a recovery of $91.6 \%$ and a $z$ score (Horwitz et al., 1980; Miller and Miller, 2005) of 0.81. Similar results were attained for $1 \%(\mathrm{v} / \mathrm{v}) \mathrm{CH}_{3} \mathrm{COOH}$ in $\mathrm{CH}_{3} \mathrm{OH}$ (15.92 $\pm 0.36 \mathrm{mg} \mathrm{kg}^{-1}$; recovery: $91.5 \% ; z$-score: 0.82 ). As observed for standard solutions, a lower recovery percentage was achieved for $70 \%(\mathrm{v} / \mathrm{v}) \mathrm{CH}_{3} \mathrm{CN}$ in $\mathrm{H}_{2} \mathrm{O}(84.4 \%)$ with a higher $z$-score value (1.51). Hence, $z$-score values $<2$ were obtained by the proposed protocol for all elution solutions, with better recoveries for those containing acetic acid, showing that the obtained results are in agreement with the certified value from the inter-laboratory collaborative determination of riboflavin in CRM NIST-1846.

The proposed procedure was also applied to commercial samples $(n=5)$, containing different amounts of macronutrients, as detailed in Table 2 . Values for riboflavin content $>90 \%$ were attained for all the samples compared to the values declared on the product label, with good precision ( $\mathrm{RSD}<0.4 \%, n=6$ ).

Considering that common laboratory equipment allows the simultaneous MISPE of at least 12 samples, with simultaneous reading of up to 26 eluate solutions in triplicate in the same microplate (Fig. S1), sample throughput is estimated as 24 samples $\mathrm{h}^{-1}$, considering that it takes half an hour for MISPE and that sample preparation and microplate preparation/reading can be performed in tandem. This is a significant improvement when compared to previously described separative methods, including HPLC (Gliszczynska-Swiglo and Koziolowa, 2000; ZafraGomez et al., 2006; Zand et al., 2012) and capillary electrophoresis (Cataldi et al., 2003), where sample throughput was between 2 and 12 determinations per hour. Using a fully automated MISPE-HPLC procedure proposed previously (Oliveira et al., 2010), sample throughput was only 6 per hour.

Regarding the analysis costs, the most expensive component would be the MISPE cartridge, with an estimated cost of 6 euros per unit. From our experience, it can be reused up to 5 times, without jeopardizing analyte recovery, also lowering analysis costs. Compared to the need for dedicated equipment and the larger amounts of solvents employed in HPLC procedures (GliszczynskaSwiglo and Koziolowa, 2000; Ndaw et al., 2000; Zafra-Gomez et al., 2006; Zand et al., 2012), the proposed method is also a more costeffective and environmentally friendly alternative. In conclusion, the proposed procedure affords a high-throughput, cost-effective procedure for determination of riboflavin in infant formula and milk samples based on molecular recognition features.

\section{Acknowledgements}

H.M.O. and L.B. acknowledge FCT (Fundação para a Ciência e a Tecnologia) for financial support through post-doc grants (SFRH/ BPD/75065/2010 and SFRH/BPD/89668/2012). This work received financial support from the European Union (FEDER funds through COMPETE) and National Funds (FCT, Fundação para a Ciência e a Tecnologia) through Projects UID/Multi/04378/2013 and UID/QUI/ $50006 / 2013$.

\section{References}

Andrés-Lacueva, C., Mattivi, F., Tonon, D., 1998. Determination of riboflavin, flavin mononucleotide and flavin-adenine dinucleotide in wine and other beverages by high-performance liquid chromatography with fluorescence detection. J. Chromatogr. A 823 (1-2), 355-363.

Cataldi, T.R.I., Nardiello, D., Carrara, V., Ciriello, R., De Benedetto, G.E., 2003. Assessment of riboflavin and flavin content in common food samples by capillary electrophoresis with laser-induced fluorescence detection. Food Chem. 82 (2), 309-314

Cataldi, T.R.I., Nardiello, D., De Benedetto, G.E., Bufo, S.A., 2002a. Optimizing separation conditions for riboflavin, flavin mononucleotide and flavin adenine dinucleotide in capillary zone electrophoresis with laser-induced fluorescence detection. J. Chromatogr. A 968 (1-2), 229-239.

Cataldi, T.R.I., Nardiello, D., Scrano, L., Scopa, A., 2002b. Assay of riboflavin in sample wines by capillary zone electrophoresis and laser-induced fluorescence detection. J. Agric. Food Chem. 50 (23), 6643-6647.

Depeint, F., Bruce, W.R., Shangari, N., Mehta, R., O’Brien, P.J., 2006. Mitochondrial function and toxicity: role of the B vitamin family on mitochondrial energy metabolism. Chem. Biol. Interact. 163 (1-2), 94-112.

Drossler, P., Holzer, W., Penzkofer, A., Hegemann, P., 2002. pH dependence of the absorption and emission behaviour of riboflavin in aqueous solution. Chem. Phys. 282 (3), 429-439.

Fishman, S.M., Christian, P., West, K.P., 2000. The role of vitamins in the prevention and control of anaemia. Public Health Nutr. 3 (2), 125-150.

Gliszczynska-Swiglo, A., Koziolowa, A., 2000. Chromatographic determination of riboflavin and its derivatives in food. J. Chromatogr. A 881 (1-2), 285-297.

Haupt, K., Mosbach, K., 2000. Molecularly imprinted polymers and their use in biomimetic sensors. Chem. Rev. 100 (7), 2495-2504.

He, C.Y., Long, Y.Y., Pan, J.L., Li, K., Liu, F., 2007. Application of molecularly imprinted polymers to solid-phase extraction of analytes from real samples. J. Biochem. Biophys. Methods 70 (2), 133-150.

Hennion, M.C., 1999. Solid-phase extraction: method development, sorbents, and coupling with liquid chromatography. J. Chromatogr. A 856 (1-2), 3-54

Henriques, B.J., Olsen, R.K., Bross, P., Gomes, C.M., 2010. Emerging roles for riboflavin in functional rescue of mitochondrial beta-oxidation flavoenzymes. Curr. Med. Chem. 17 (32), 3842-3854. 
Horwitz, W., Kamps, L.R., Boyer, K.W., 1980. Quality assurance in the analysis of food for trace constituents. J. AOAC Int. 63 (6), 1344-1354.

Hustad, S., Ueland, P.M., Vollset, S.E., Zhang, Y., Bjorke-Monsen, A.L., Schneede, J., 2000. Riboflavin as a determinant of plasma total homocysteine: effect modification by the methylenetetrahydrofolate reductase $\mathrm{C} 677 \mathrm{~T}$ polymorphism. Clin. Chem. 46 (8), 1065-1071.

Kadara, R.O., Haggett, B.G.D., Birch, B.J., 2006. Disposable sensor for measurement of vitamin B-2 in nutritional premix, cereal, and milk powder. J. Agric. Food Chem. 54 (14), 4921-4924.

Koop, J., Monschein, S., Macheroux, E.P., Knaus, T., Macheroux, P., 2014. Determination of free and bound riboflavin in cow's milk using a novel flavin-binding protein. Food Chem. 146, 94-97.

Manesiotis, P., Borrelli, C., Aureliano, C.S.A., Svensson, C., Sellergren, B., 2009. Water-compatible imprinted polymers for selective depletion of riboflavine from beverages. J. Mater. Chem. 19 (34), 6185-6193.

Manesiotis, P., Hall, A.J., Courtois, J., Irgum, K., Sellergren, B., 2005. An artificial riboflavin receptor prepared by a template analogue imprinting strategy. Angew. Chem. Int. Ed. 44 (25), 3902-3906.

Marriage, B., Clandinin, M.T., Glerum, D.M., 2003. Nutritional cofactor treatment in mitochondrial disorders. J. Am. Diet. Assoc. 103 (8), 1029-1038.

Miller, J.N., Miller, J.C., 2005. Statistics and Chemometrics for Analytical Chemistry, 5th ed. Pearson, Harlow, UK.

Ndaw, S., Bergaentzle, M., Aoude-Werner, D., Hasselmann, C., 2000. Extraction procedures for the liquid chromatographic determination of thiamin, riboflavin and vitamin B-6 in foodstuffs. Food Chem. 71 (1), 129-138.

Oliveira, H.M., Segundo, M.A., Lima, J.L.F.C., Miro, M., Cerda, V., 2010. Exploiting automatic on-line renewable molecularly imprinted solid-phase extraction in lab-on-valve format as front end to liquid chromatography: application to the determination of riboflavin in foodstuffs. Anal. Bioanal. Chem. 397 (1), 77-86.

Ortega, R.M., Quintas, M.E., Martinez, R.M., Andres, P., Lopez-Sobaler, A.M., Requejo, A.M., 1999. Riboflavin levels in maternal milk: the influence of vitamin B-2 status during the third trimester of pregnancy. J. Am. Coll. Nutr. 18 (4), 324-329.

Pichon, V., 2007. Selective sample treatment using molecularly imprinted polymers. J. Chromatogr. A 1152 (1-2), 41-53.

Powers, H.J., 2003. Riboflavin (vitamin B-2) and health. Am. J. Clin. Nutr. 77 (6), 1352-1360.

Scotter, M.J., 2011. Methods for the determination of European Union-permitted added natural colours in foods: a review. Food Addit. Contam. Part A-Chem. Anal. Control Expo. Risk Assess. 28 (5), 527-596.

Segundo, M.A., Osório, M.V., Oliveira, H.M., Barreiros, L., Magalhães, L.M., 2012. Assays of riboflavin in food using solid-phase extractionIn: B Vitamins and Folate: Chemistry, Analysis, Function and Effects, pp. 271-284.

Vergani, L., Barile, M., Angelini, C., Burlina, A.B., Nijtmans, L., Freda, M.P., Brizio, C., Zerbetto, E., Dabbeni-Sala, F., 1999. Riboflavin therapy - biochemical heterogeneity in two adult lipid storage myopathies. Brain 122, 2401-2411.

Zafra-Gomez, A., Garballo, A., Morales, J.C., Garcia-Ayuso, L.E., 2006. Simultaneous determination of eight water-soluble vitamins in supplemented foods by liquid chromatography. J. Agric. Food Chem. 54 (13), 4531-4536.

Zand, N., Chowdhry, B.Z., Pullen, F.S., Snowden, M.J., Tetteh, J., 2012. Simultaneous determination of riboflavin and pyridoxine by UHPLC/LC-MS in UK commercial infant meal food products. Food Chem. 135 (4), 2743-2749. 